\title{
Caregiving Needs Are Unmet for Many Older Homeless Adults: Findings from the HOPE HOME Study
}

\author{
Wagahta Semere, $M D, M H S^{1,2}$, Lauren Kaplan, $P h D^{2}$, Karen Valle, $M S^{2}$, \\ David Guzman, $\mathrm{MSPH}^{2}$, Claire Ramsey, MA, JD³, Cheyenne Garcia, $B A^{2}$, and \\ Margot Kushel, MD²
}

'Division of General Internal Medicine, University of California, San Francisco (UCSF) and Zuckerberg San Francisco General Hospital and Trauma Center, San Francisco, CA, USA; ${ }^{2}$ UCSF Center for Vulnerable Populations at Zuckerberg San Francisco General Hospital and Trauma Center, San Francisco, CA, USA; ${ }^{3}$ Justice in Aging, Oakland, CA, USA.

BACKGROUND: The homeless population is aging, with early onset of cognitive and functional impairments. It is unclear whether older homeless adults receive caregiving assistance that could prevent long-term disability.

OBJECTIVE: We describe characteristics of older homeless-experienced adults with caregiving need and determine factors associated with having unmet need.

DESIGN AND PARTICIPANTS: Cross-sectional analysis of a longitudinal study, Health Outcomes in People Experiencing Homelessness in Older Middle Age (HOPE HOME), examining health, life course events, and functional status among older homeless-experienced (i.e., currently and recently homeless) adults. We recruited 350 homeless adults (July 2013-June 2014) and an additional 100 (August 2017 to July 2018) in Oakland, California; this study includes 303 participants who completed caregiving interviews.

MEASUREMENTS: We defined caregiving need as difficulty with activities of daily living (ADLs), instrumental activities of daily living (IADLs), falls, Short Physical Performance Battery (SPPB) score $<10$, or Modified Mini-Mental State (3MS) exam impairment. We defined unmet need as having caregiving need and reporting not receiving caregiving assistance in the last 6 months. Using logistic regression, we analyzed associations between respondent characteristics and unmet caregiving need.

RESULTS: Among 303 participants, the mean age was $61.3 \pm 5.0$ years; $73 \%$ were men and $82 \%$ were Black. Eighty-one percent had caregiving needs, and in $82 \%$ of those, their caregiving needs were unmet. Better selfrated health (AOR 2.13, CI [1.02-4.46], $p=0.04$ ) and being a man (AOR 2.30, CI [1.12-4.69], $p=0.02$ ) were associated with higher odds of unmet need. Moderate or high-risk substance use (AOR 0.47, CI [0.23, 0.94], $p=$ 0.03 ) was associated with lower odds of unmet need.

Prior Presentations: Early findings from this manuscript were accepted as an oral presentation for the 2020 Society of General Internal Medicine annual meeting, but were not presented given cancellation of the meeting due to the coronavirus (COVID-19) pandemic.

Received July 26, 2021

Accepted January 26, 2022

Published online February 15, 2022
CONCLUSIONS: Older homeless-experienced adults have high prevalence of unmet caregiving need. Interventions that increase caregiving access for homeless-experienced individuals may help avoid poor health outcomes and costly long-term-care needs due to untreated disabilities.

KEY WORDS: homeless; older adults; caregiving; caregivers.

J Gen Intern Med 37(14):3611-9

DOI: $10.1007 / \mathrm{s} 11606-022-07438-z$

(C) The Author(s) under exclusive licence to Society of General Internal Medicine 2022

\section{INTRODUCTION}

Adults over the age of 50 comprise a growing proportion of the individual adult homeless population. ${ }^{1}$ They have a high prevalence of geriatric conditions, including cognitive impairment, functional disability, and falls which indicate caregiving needs. ${ }^{2}$ Homeless-experienced (i.e., currently or formerly homeless) individuals experience geriatric conditions approximately 20 years earlier than the general population. ${ }^{2,3}$ High prevalence of co-existing mental health problems and substance use disorders further contributes to their vulnerabilities. ${ }^{4}$ Experiencing homelessness can have implications for disability and poor health outcomes even once individuals are housed. $^{5,6}$

Homeless-experienced adults have difficulty accessing formal caregiving services, such as nursing or home health aide support. ${ }^{7}$ Home and Community Based Services (HBCS) provide opportunities for Medicaid recipients to receive services in their home or community rather than in institutions. HCBS accounts for over half of overall Medicaid long-term care spending but access to services is limited for individuals without a home. ${ }^{8}$ Homeless-experienced adults face barriers to informal caregiving (i.e., unpaid support from family or friends), due to disrupted social networks from frequent relocations, trauma, substance use, and mental health disorders. ${ }^{9}$ Homeless-experienced adults' family and friends are often impoverished and struggle to provide care. ${ }^{9}$ Homelessexperienced individuals' unmet caregiving needs may lead to disabilities that require costly long-term care. ${ }^{10}$ 
Caregivers, formal and informal, can meet these caregiving needs and decrease reliance on institutional care. Yet, there has been limited research examining the prevalence of caregiving need among homeless-experienced populations. ${ }^{11,12}$ Understanding the extent of these needs could allow for better assessment of their risk for disability and poor health outcomes.

In this study, we (1) describe the characteristics of older homeless-experienced adults with caregiving need and (2) determine sociodemographic and health factors associated with having unmet caregiving need.

\section{METHODS}

\section{Study Overview}

The Health Outcomes in People Experiencing Homelessness in Older Middle agE (HOPE HOME) study is a longitudinal study of health, life course events, and functional status among older adults who were homeless at study entry. ${ }^{13}$ The University of California, San Francisco Institutional Review Board approved all study activities.

\section{Sample and Recruitment}

In wave 1 of HOPE HOME, we used population-based sampling to recruit 350 homeless individuals age 50 and older in Oakland, California, from July 2013 to June $2014 .^{13,14}$ We recruited participants from all overnight homeless shelters serving single adults over age $25(n=5)$, all low-cost meal programs serving at least three meals per week $(n=5)$, one recycling center, and places where unsheltered homeless individuals lived. We constructed our sampling frame to approximate the source population; we randomly selected potential participants at each recruitment site. ${ }^{13,15}$ In wave 2, we applied the same recruitment strategy to recruit 100 additional homeless individuals aged 53 and over from August 2017 to July 2018.

Participants completed study interviews every 6 months and remained in the study whether or not they regained housing. We analyzed data from the first interview for wave 2 participants and a concurrent follow-up interview for wave 1 participants. During this interview, wave 1 and wave 2 participants completed a caregiving questionnaire, which we introduced in 2017-2018 (Fig. 1).

\section{Study Design and Population}

To be eligible for HOPE HOME, participants had to meet age criteria, be homeless at study enrollment, be English speaking, and be able to give written informed consent using a teachback method. ${ }^{16,17}$ We compensated participants $\$ 25$ for the screening and enrollment interview, $\$ 5$ for monthly check-ins, and $\$ 20$ for follow-up interviews.

\section{Measures}

We collected participants' sociodemographic characteristics including age, gender, race/ethnicity, marital/partner status, highest level of education, employment status, and income in the last 30 days.

\section{Homeless and Housing Status}

At each visit, we categorized participants as homeless versus not homeless, according to federal Homeless Emergency Assistance and Rapid Transition to Housing (HEARTH) Act criteria. ${ }^{16}$ We separately asked participants where they were currently staying and categorized responses as unsheltered, sheltered, in permanent housing for formerly homeless individuals, institution (i.e., skilled rehabilitation facility, nursing home, or sober living facility), transitional housing, hotel/ motel, or apartment/house.

\section{Social Support}

We asked participants how many close friends or family members they had to confide in. ${ }^{18} \mathrm{We}$ then categorized participants as having $0,1-5$, or $\geq 6$ confidants.

\section{Chronic Conditions}

We categorized participants' health as poor or fair versus good, very good, or excellent, based on self-report. ${ }^{19} \mathrm{We}$ asked participants to self-report chronic medical conditions and grouped these as cardiovascular disease, pulmonary disease, chronic kidney disease, liver disease, diabetes, HIV/ AIDS, and cancer. We categorized participants as having 0 , $1-2$, or $\geq 3$ chronic conditions.

\section{Substance Use and Mental Health}

We categorized participants who reported consuming $\geq 6$ drinks on one occasion monthly or more often as binge drinkers. ${ }^{20,21}$ To evaluate use of cocaine, amphetamines, or opioids, we administered the World Health Organization's (WHO) Alcohol, Smoking, and Substance Involvement Screening Test (ASSIST); we classified scores $\geq 4$ as moderate- to high-risk use and $0-3$ as low-risk use. ${ }^{22}$ Participants self-reported whether they were ever hospitalized for a mental health problem.

\section{Caregiving Need}

We asked participants, "What things did you get help with?" and allowed them to select multiple options from a list of 5 activities of daily living (ADLs - bathing, dressing, eating, transferring, or toileting) and 6 instrumental activities of daily living (IADLs, assessed using the Brief Instrumental Functioning Scale - managing medications, filling out applications for benefits, managing finances, using public transportation, setting up job interviews, finding an attorney). ${ }^{23,24}$ For each ADL and IADL, we asked participants whether they needed 


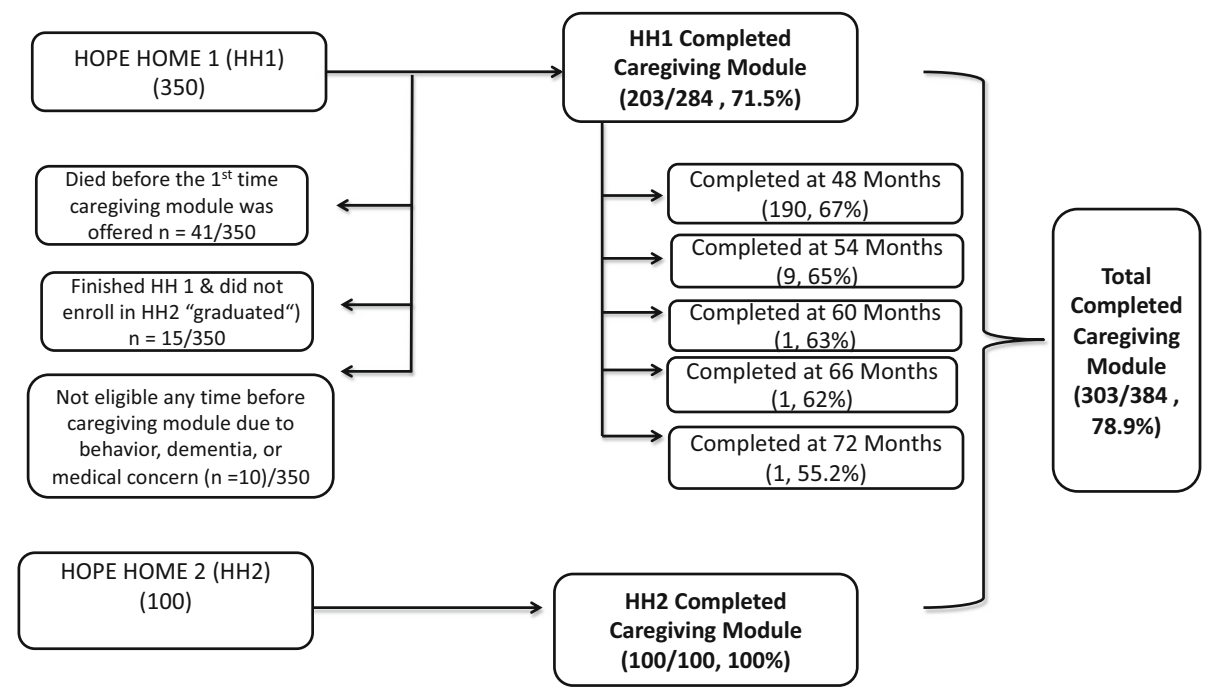

Figure 1 Recruitment flow chart. The figure shows the number of HOPE HOME participants from waves 1 and 2 who completed the caregiving module.

"no help," "a little help," "a lot of help," or "someone to do it for me." We classified participants as requiring any ("a lot of help" or "someone to do it for me") or little to no ("a little help" or "no help") assistance performing $\geq 1$ ADL and $\geq 1$ IADL.

Participants reported experiencing any falls in the past 6 months. We administered the Short Physical Performance Battery (SPPB) tool to assess lower extremity function and considered an SPPB score $<10$ to indicate significantly limited lower extremity function. ${ }^{25}$

To assess cognitive function, we used the Modified MiniMental State Exam (3MS). We categorized 3MS scores below the 7 th percentile as cognitive impairment. ${ }^{26,27}$

For our primary outcome, we defined caregiving need as experiencing any one of the following in the past 6 months: (1) difficulty with $\geq 1 \mathrm{ADL}$, (2) difficulty with $\geq 1 \mathrm{IADL},(3) \geq 1$ fall, (4) SPPB score $<10$, or (5) $3 \mathrm{MS}$ score $<7^{\text {th }}$ percentile. We developed our definition for caregiving need based on definitions used in nationally representative studies of older adults that examined caregiving need and functional limitations. $^{28-32}$

\section{Unmet Caregiving Need}

We asked participants whether, in the last 6 months, anyone helped them with things like "bathing, dressing, eating, getting in and out of bed, using the toilet, moving around the house, getting to places outside the house, laundry, shopping or anything else." We defined unmet caregiving need as meeting the definition for caregiving need but reporting not receiving caregiving assistance in the past 6 months. We adapted this definition from the National Health and Aging Trends Study (NHATS), which defines unmet need as an inability to perform a task due to the task being too difficult or not having assistance. $^{33}$

\section{Caregiving Characteristics}

Participants reported characteristics of caregiving they received. We categorized participants' relationship to their caregiver (i.e., partner, relative, friend), and whether their caregiver was paid or unpaid. For paid caregivers, we specified who paid them (In-Home Supportive Services [IHSS], Veteran Affairs [VA], other government program, insurance, family, or participant). We calculated the estimated hours of caregiving assistance received over the last month, by asking participants to estimate the number of days and hours per day during the last month their caregiver spent helping them. We specified the ADL and IADL tasks for which the caregiver helped.

When participants had multiple caregivers, we defined primary caregivers as those who provided the greatest number of hours of assistance over the last month; we described the characteristics of participants' primary caregiver and caregiving situation.

\section{Statistical Analysis}

We used descriptive statistics to present participant sociodemographic and health characteristics, and to describe characteristics of caregiving received. Using chi-square and Student $t$ tests, we compared characteristics of participants with and without unmet caregiving needs.

We restricted the sample to those with caregiving need and estimated multivariable logistic regression models examining the odds of having unmet caregiving. We included all independent variables with two-sided $p$ values $<$ 0.20 in the starting model and applied backwards elimination, retaining variables with two-sided $p$ values $<0.05$. We performed all statistical analysis using SAS version 9.4. 


\section{RESULTS}

\section{Participant Characteristics $(n=303)$}

Overall, 303 participants (203 from wave 1 and 100 from wave 2 ) completed the caregiving module (Fig. 1). The median age was 58 years; $73 \%$ were men and $82 \%$ were Black. Almost all (91\%) were single or unpartnered; nearly onequarter reported not having any confidants. Fifty-nine percent of participants were currently homeless. Seventy-three percent reported having chronic conditions, most frequently cardiovascular diseases (73\%) and arthritis (53\%); $37 \%$ had moderate-high-risk illicit drug use and $10 \%$ were binge drinkers. Half of participants reported their health as fair or poor. Eighty-one percent $(n=245)$ of participants had caregiving need.

\section{Characteristics of Participants with Caregiving Need $(n=245)$}

Of the 245 participants who had caregiving need, 55\% had difficulty with $\geq 1 \mathrm{ADL}$ and $39 \%$ with $\geq 1$ IADL. One-third (32\%) experienced a fall in the last 6 months, $71 \%$ had an SPPB score < 10, and 22\% had 3MS impairment (Table 1). Eighty-two percent of those with caregiving need did not receive caregiving in the past 6 months.

\section{Characteristics of Caregiving Received $(n=45)$}

Of the 45 participants who reported receiving caregiving, 28 participants received paid caregiving; the majority $(n=$ 21) of caregivers received payment through IHSS (Table 2). Participants reported that their caregivers spent

Table 1 Participant Characteristics by Caregiving Need $(n=303)$

\begin{tabular}{|c|c|c|c|c|}
\hline \multirow[t]{2}{*}{ Characteristics } & \multirow{2}{*}{$\begin{array}{l}\text { Overall } \\
(n=303)\end{array}$} & \multicolumn{3}{|c|}{ Caregiving need,* no. $(\%)$} \\
\hline & & $\begin{array}{l}\text { Yes } \\
(n=245)\end{array}$ & $\begin{array}{l}\text { No } \\
(n=58)\end{array}$ & $p$ value \\
\hline Age, mean $\pm \mathrm{SD}$ & $61.3 \pm 5.0$ & $61.4 \pm 5.0$ & $60.7 \pm 4.9$ & 0.32 \\
\hline Women & $81(26.7)$ & $74(30.2)$ & $7(12.1)$ & 0.05 \\
\hline \multicolumn{4}{|l|}{ Race/ethnicity } & 0.64 \\
\hline Black & $249(82.2)$ & $198(80.8)$ & $51(87.9)$ & \\
\hline White & $26(8.6)$ & $23(9.4)$ & $3(5.2)$ & \\
\hline Hispanic/Latino & $15(5.0)$ & $13(5.3)$ & $2(3.4)$ & \\
\hline Mixed & $13(4.3)$ & $11(4.5)$ & $2(3.4)$ & \\
\hline Homeless & $178(58.7)$ & $147(60.0)$ & $31(53)$ & 0.36 \\
\hline \multicolumn{4}{|l|}{ Current housing } & 0.02 \\
\hline Unsheltered/shelter & $154(50.8)$ & $129(52.7)$ & $25(43.1)$ & \\
\hline Transitional housing & $12(4.0)$ & $12(4.9)$ & & \\
\hline Permanent housing for homeless & $24(7.9)$ & $16(6.5)$ & $8(13.8)$ & \\
\hline Hotel $/$ motel & $9(3.0)$ & $5(2.0)$ & $4(6.9)$ & \\
\hline Apartment/house & $96(31.7)$ & $75(30.6)$ & $21(36.2)$ & \\
\hline Institution & $8(2.6)$ & $8(3.3)$ & 0 & \\
\hline Single/never married & $182(60.1)$ & $147(60.0)$ & $35(60.3)$ & 0.46 \\
\hline \multicolumn{4}{|l|}{ Education } & 0.02 \\
\hline Less than high school & $83(27.4)$ & $75(30.6)$ & $8(13.8)$ & \\
\hline High school/GED & $49(16.2)$ & $35(14.3)$ & $14(24.1)$ & \\
\hline More than high school & $167(55.1)$ & $131(53.5)$ & $36(62.1)$ & \\
\hline Worked for pay in the last 30 days & $33(10.9)$ & $20(8.2)$ & $13(22.4)$ & $<0.01$ \\
\hline Income $\geq \$ 1000 /$ month & $60(19.8)$ & $51(20.8)$ & $9(15.5)$ & 0.36 \\
\hline Ever hospitalized for mental health problems & $29(9.6)$ & $28(11.4)$ & $1(1.7)$ & 0.02 \\
\hline Binge drinking & $27(8.9)$ & $23(9.4)$ & $4(6.9)$ & 0.51 \\
\hline \multicolumn{4}{|l|}{ Problematic use of cocaine, opioids, or amphetamine } & 0.45 \\
\hline Moderate-high risk $(\geq 4)$ & $112(37.0)$ & $93(38.0)$ & $19(32.8)$ & \\
\hline Any confidants & $230(75.9)$ & $183(74.7)$ & $47(81.0)$ & 0.27 \\
\hline \multicolumn{4}{|l|}{ Number of confidants } & 0.08 \\
\hline $1-5$ confidants & $203(67.0)$ & $165(67.3)$ & $38(65.5)$ & \\
\hline$\geq 5$ confidants & $26(8.6)$ & $17(6.9)$ & $9(15.5)$ & \\
\hline \multicolumn{4}{|l|}{ Self-reported health status } & $<0.01$ \\
\hline \multirow{2}{*}{\multicolumn{4}{|c|}{ Number of chronic diseases }} & \\
\hline & & & & 0.02 \\
\hline $1-2$ diseases & $180(59.4)$ & $151(61.6)$ & $29(50.0)$ & \\
\hline \multirow{2}{*}{\multicolumn{5}{|c|}{ Chronic disease type }} \\
\hline & & & & \\
\hline Liver disease & $75(24.8)$ & $64(26.1)$ & $11(19.0)$ & 0.26 \\
\hline Kidney disease & $25(8.3)$ & $23(9.4)$ & $2(3.4)$ & 0.14 \\
\hline HIV/AIDS & $17(5.6)$ & $13(5.3)$ & $4(6.9)$ & 0.64 \\
\hline Lung disease & $104(34.3)$ & $92(37.6)$ & $12(20.7)$ & 0.02 \\
\hline Diabetes & $71(23.4)$ & $57(23)$ & $14(24.1)$ & 0.89 \\
\hline Arthritis & $161(53.1)$ & $132(53.9)$ & $29(50.0)$ & 0.57 \\
\hline Cardiovascular disease & $222(73.3)$ & $185(75.5)$ & $37(63.8)$ & 0.07 \\
\hline
\end{tabular}

*Caregiving need is calculated as meeting any one of the following criteria in the past 6 months: (1) difficulty with one or more activities of daily living (ADLs), (2) difficulty with one or more instrumental activities of daily living (IADLs), (3) one or more falls, (4) a Short Physical Performance Battery $(S P P B)$ score $<10$, or (5) a Modified Mini-Mental State (3MS) exam score below the 7th percentile 
Table 2 Caregiving Characteristics for Those Who Received Caregiving $(n=45)$

\begin{tabular}{ll}
\hline \hline Characteristics & No. (\%) \\
\hline Tasks received help with* & \\
ADL & \\
Bathing & $23(51)$ \\
Dressing & $26(58)$ \\
Eating & $8(18)$ \\
Getting in and out of bed & $18(40)$ \\
Using the toilet & $11(24)$ \\
IADL & \\
Managing medications & $5(11)$ \\
Filling out applications for benefits & $11(24)$ \\
Managing finances & $6(13)$ \\
Using public transportation & $7(16)$ \\
Setting up job interviews & $6(13)$ \\
Finding an attorney & $16(36)$ \\
Who helped & \\
Partner & $3(7)$ \\
Child & $5(11)$ \\
Parent & $1(2)$ \\
Other relative & $2(5)$ \\
Roommate & 0 \\
Paid worker/housekeeper & $20(45)$ \\
Friend & $1(2)$ \\
Someone/service at residence & $8(18)$ \\
Other & $4(9)$ \\
Number of caregiving hours per month (mean \pm SD) & $73.22 \pm 122.0$ \\
Paid caregiving & $28(64)$ \\
Source of caregiving payment & \\
IHSS & $21(81)$ \\
VA program & $1(4)$ \\
Other government program & 0 \\
Insurance & $2(8)$ \\
Self & $1(4)$ \\
Family & 0 \\
Other & $1(4)$ \\
Have additional caregiver & $8(18)$ \\
\hline &
\end{tabular}

VA Veterans Affairs, IHSS In-Home Support Services

*Tasks for which participants responded that they needed "a lot of help" or "someone to do it for me"

an average $73.2( \pm 122.0) \mathrm{h}$ per month caregiving. Participants received assistance with activities including bathing $(n=23)$, dressing $(n=26)$, and finding an attorney $(n=16)$ (Table 2).

\section{Association of Participant Characteristics and Unmet Caregiving Need}

In bivariate analyses, those with unmet caregiving need were more likely to be homeless ( $64 \%$ vs $44 \%, p=0.02$ ); current housing categories were associated with unmet need $(p<0.01)$. Participants who were single $(57 \%$ vs $76 \%, p=$ $0.04)$ and had moderate- or high-risk substance use (35\% vs $51 \%, p=0.03$ ) were less likely to have unmet need (Table 3). In multivariable models, reporting good, very good, or excellent health (AOR 2.13, CI [1.02-4.46], $p=$ 0.04 ) and being a man (AOR 2.30, CI [1.12-4.69], $p=0.02$ ) was associated with higher odds of unmet need. Having moderate- or high-risk substance use (AOR 0.47, CI [0.23-0.94], $p=0.03$ ) was associated with lower odds of unmet need (Table 4).

\section{DISCUSSION}

In a cohort of older homeless-experienced adults, we found that $81 \%$ of participants had caregiving need but less than $20 \%$ of those with caregiving need received assistance. Given their high risk for institutional care, homeless-experienced adults can benefit from programs that support access to caregiving in the community. Such strategies could potentially delay or avoid institutional care.

In national surveys, approximately $5-20 \%$ of housed adults over age 65 reported difficulty with self-care and $10 \%$ had cognitive impairments. ${ }^{34,35}$ In our sample (median age 58 years), over half had difficulty with self-care and over $20 \%$ had cognitive impairment. In previous work, we found that homeless-experienced adults had similar patterns of decline and persistence in functional impairments as those in older adults in the general community, suggesting that our participants' caregiving needs likely reflect those of older populations. This reinforces the need for interventions to reduce reliance on institutional care for homeless-experienced adults. ${ }^{36,37}$

In national studies, about $20 \%$ of older adults report having unmet caregiving needs compared to $82 \%$ of homelessexperienced older adults in our study with unmet caregiving needs. ${ }^{35,38,39}$ This fourfold difference in unmet caregiving need highlights gaps in policies and practices for access to caregiving services among homeless-experienced adults. Home and Community-Based Services (HCBS) are designed to decrease reliance on institutional care by providing individuals with services, including assistance with ADLs and IADLs, that keep them living safely in their homes and their communities. ${ }^{8}$ People experiencing homelessness often face significant barriers to receipt of Medicaid-funded caregiving support despite their need for these services. These barriers range from statutory barriers restricting care to sheltered individuals to practical barriers created by cumbersome application processes.

For example, unsheltered homeless individuals are ineligible for California's In-Home Support Services (IHSS) program - the state's largest Medicaid HCBS program serving over 640,000 residents. IHSS providers help with a range of services including personal care, paramedical tasks, and transportation to medical appointments. ${ }^{40}$ While many older homeless individuals may have functional limitations that require caregiving, they do not have an address of residence, which excludes them from receiving IHSS. ${ }^{41}$ The IHSS application process requires demonstrating Medi-Cal eligibility and having a health provider complete a Health Care Certification form. ${ }^{40}$ Enrolled individuals must hire, pay, and monitor their IHSS provider; this can be challenging for adults with cognitive impairment or behavioral problems. Providing navigators to assist throughout the application process, hiring, and supervising of caregivers may improve access and retention of potential IHSS recipients who are homeless. 
Table 3 Characteristics of Those Who Had a Caregiving Need at First Full Interview by Unmet Need $(n=\mathbf{2 4 5})$

\begin{tabular}{|c|c|c|c|c|}
\hline \multirow[t]{2}{*}{ Characteristics } & \multirow{2}{*}{$\begin{array}{l}\text { Overall } \\
(n=245)\end{array}$} & \multicolumn{3}{|c|}{ Unmet need, no. (\%) } \\
\hline & & $\begin{array}{l}\text { Yes } \\
(n=200)\end{array}$ & $\begin{array}{l}\text { No } \\
(n=45)\end{array}$ & $p$ value \\
\hline Age, mean $\pm \mathrm{SD}$ & $61.43 \pm 5.0$ & $61.40 \pm 4.9$ & $61.58 \pm 5.4$ & 0.83 \\
\hline Women & $74(30.2)$ & $55(27.5)$ & $19(42.2)$ & 0.05 \\
\hline \multicolumn{4}{|l|}{ Race/ethnicity } & 0.76 \\
\hline Black & $198(80.8)$ & $161(80.5)$ & $37(82.2)$ & \\
\hline White & $23(9.4)$ & $18(9.0)$ & $5(11.1)$ & \\
\hline Hispanic/Latino & $13(5.3)$ & $12(6.0)$ & $1(2.2)$ & \\
\hline Mixed & $11(4.5)$ & $9(4.5)$ & $2(4.4)$ & \\
\hline Homeless & $147(60.0)$ & $127(63.5)$ & $20(44.4)$ & 0.02 \\
\hline \multicolumn{4}{|l|}{ Current housing } & $<0.01$ \\
\hline Unsheltered/shelter & $129(52.7)$ & $111(55.5)$ & $18(40.0)$ & \\
\hline Transitional housing & $12(4.9)$ & $11(5.5)$ & $1(2.2)$ & \\
\hline Permanent housing for homeless & $16(6.5)$ & $10(5.0)$ & $6(13.3)$ & \\
\hline Hotel/motel & $5(2.0)$ & $3(1.5)$ & $2(4.4)$ & \\
\hline Apartment/house & $75(30.6)$ & $62(31.0)$ & $13(28.9)$ & \\
\hline Institution & $8(3.3)$ & $3(1.5)$ & $5(11.1)$ & \\
\hline Single/never married & $147(60.0)$ & $113(56.5)$ & $34(75.6)$ & 0.04 \\
\hline \multicolumn{4}{|l|}{ Education } & 0.76 \\
\hline Less than high school & $75(30.6)$ & $61(30.5)$ & $14(31.1)$ & \\
\hline High school/GED & $35(14.3)$ & $30(15.0)$ & $5(11.1)$ & \\
\hline More than high school & $131(53.5)$ & $105(52.5)$ & $26(57.8)$ & \\
\hline Worked for pay in last 30 days & $20(8.2)$ & $19(9.5)$ & $1(2.2)$ & 0.11 \\
\hline Income $\geq \$ 1000$ & $51(20.8)$ & $43(21.5)$ & $8(17.8)$ & 0.58 \\
\hline Binge drinking & $23(9.4)$ & $22(11.0)$ & $1(2.2)$ & 0.06 \\
\hline Ever hospitalized for mental health problems & $28(11.4)$ & $22(11.0)$ & $6(13.3)$ & 0.66 \\
\hline \multicolumn{4}{|l|}{ Problematic use of cocaine, opioids, or amphetamine } & 0.03 \\
\hline Moderate-high risk $(\geq 4)$ & $93(38)$ & $70(35.0)$ & $23(51.1)$ & \\
\hline Any confidant & $183(74.7)$ & $145(72.5)$ & $38(84.4)$ & 0.13 \\
\hline \multicolumn{4}{|l|}{ Number of confidants } & 0.29 \\
\hline $1-5$ confidants & $165(67.3)$ & $131(65.5)$ & $34(75.6)$ & \\
\hline$\geq 5$ confidants & $17(6.9)$ & $13(6.5)$ & $4(8.9)$ & \\
\hline \multicolumn{4}{|l|}{ Self-reported health status } & 0.08 \\
\hline Fair/poor & $140(57.1)$ & $109(54.5)$ & $31(68.9)$ & \\
\hline Falls in past 6 months & $79(32.2)$ & $58(29.0)$ & $21(46.7)$ & 0.02 \\
\hline$\geq 1$ ADL difficulty & $133(54.3)$ & $94(47.0)$ & 39 (86.7) & $<0.01$ \\
\hline$\geq 1$ IADL difficulty & $96(39.2)$ & $71(35.5)$ & $25(55.6)$ & 0.01 \\
\hline SPPB score $<10$ & $175(71.4)$ & $135(67.5)$ & $40(88.9)$ & $<0.01$ \\
\hline 3MS impaired $(<7$ th percentile) & $47(19.2)$ & $43(21.5)$ & $4(8.9)$ & 0.07 \\
\hline \multicolumn{4}{|l|}{ Number of chronic diseases } & 0.01 \\
\hline $1-2$ diseases & $151(61.6)$ & $120(60.0)$ & $31(68.9)$ & \\
\hline$\geq 3$ diseases & $36(14.7)$ & $25(12.5)$ & $11(24.4)$ & \\
\hline \multicolumn{5}{|l|}{ Chronic disease type } \\
\hline Liver disease & $64(26.1)$ & $52(26.0)$ & $12(26.7)$ & 0.93 \\
\hline Kidney disease & $23(9.4)$ & $19(9.5)$ & $4(8.9)$ & 0.90 \\
\hline HIV/AIDS & $13(5.3)$ & $10(5.0)$ & $3(6.7)$ & 0.65 \\
\hline Lung disease & $92(37.6)$ & $67(33.5)$ & $25(55.6)$ & 0.01 \\
\hline Diabetes & $57(23.3)$ & $43(21.5)$ & $14(31.1)$ & 0.17 \\
\hline Arthritis & $132(53.9)$ & $102(51.0)$ & $30(66.7)$ & 0.06 \\
\hline Cardiovascular disease & $185(75.5)$ & $145(72.5)$ & $40(88.9)$ & 0.02 \\
\hline
\end{tabular}

ADL activities of daily living, IADL independent activity of daily living, SPPB Short Physical Performance Battery, 3MS Modified Mini-Mental State

Our findings suggest that formerly homeless older adults continue to face barriers to receiving IHSS even once

Table 4 Multivariable Analysis of Participant Characteristics Associated with Unmet Need

\begin{tabular}{lcc}
\hline \hline Characteristic & $\begin{array}{l}\text { Adjusted odds ratio } \\
\text { (95\% CI) }\end{array}$ & $\boldsymbol{p}$ value \\
\hline Male & $2.30(1.12-4.69)$ & 0.02 \\
$\begin{array}{l}\text { Homeless } \\
\text { Problematic use of cocaine, opioids, or amphetamine } \\
\quad \text { Low risk (0-3) }\end{array}$ & 0.08 \\
$\begin{array}{l}\text { Self-reported health status } \\
\text { Good/very good/excellent }\end{array}$ & $2.13(1.05-4.33)$ & 0.03 \\
\hline
\end{tabular}

$p<0.05$ considered statistically significant housed, including navigating a complex application process and managing hired caregivers. It is possible that expansion of pilot efforts to proactively expand IHSS to permanent supportive housing by leveraging trained staff with experience equipping formerly homeless individuals with the skills to navigate these barriers could alleviate this disparity. ${ }^{42}$ Ensuring equitable access to caregiving services for homeless-experienced individuals requires addressing structural barriers. ${ }^{43}$

In California, approximately $72 \%$ of people experiencing homelessness are unsheltered. ${ }^{44}$ Homeless-experienced adults' friends and family are likely to experience deep poverty and have low household incomes, making it difficult for their social networks to provide unpaid care. ${ }^{9}$ Individuals who 
stay in congregate shelters face additional barriers. Shelter staff do not offer formal caregiving services and shelter policies restrict visitors, such that paid or informal caregivers cannot enter to offer residents assistance. Lifting visitor restrictions for caregivers could allow access to care recipients in need. ${ }^{45}$ While homelessness was associated with lack of receipt of needed caregiving in bivariate models, it was not significant in adjusted models. Homelessness is a dynamic state. We found that those who regained housing remained at risk of unmet caregiving needs.

Among those with caregiving needs, we found that men were more likely to have unmet need. This finding is consistent with work showing that while men present with higher levels of need when compared to women, men are less likely to access home care services and more likely to be admitted to long-term care. ${ }^{46}$ Older men experiencing homelessness may be less likely to seek, and thus receive, care. Participants who rated their health as better were more likely to have unmet caregiving needs. It is possible that being in better health facilitates the ability to "get by" without assistance due to having fewer overall needs or better ability to navigate existing needs. Yet, there are significant risks to not receiving assistance with the impairments we examined. Impairments in ADLs and IADLs are significant contributors to overall frailty and predictors of long-term disability. ${ }^{47-49}$ Homelessexperienced adults with caregiving needs who go without assistance may be at high risk for disabilities that lead to long-term care.

With the passage of the Affordable Care Act, more individuals now qualify for Medicaid, which could lead to a substantial increase in spending on institutional care among people experiencing homelessness. ${ }^{50}$ Given that the average per person annual costs of skilled nursing facility and long-term facility care are as high as $\$ 50,000$ to $\$ 100,000$, there is a need to develop strategies to reduce this potential spending. ${ }^{10}$ Community-based programs supported through Medicaid range from $\$ 5000$ to $\$ 12,000$ per individual in estimated average costs per year, one-fifth to one-tenth the cost spent on long-term care. ${ }^{51}$ Expanding such programs can increase access to caregiving and offer care recipients benefits, including maintaining autonomy and social connections.

Many community-based caregiving programs are not structured to accommodate homeless individuals. Recognizing the need for increased access to and funding for HCBS, the Biden administration's American Rescue Plan Act included a significant temporary increase in federal funding for HCBS. ${ }^{52,53}$ This increased spending requires states to enhance, expand, and strengthen Medicaid-funded HCBS. ${ }^{54}$ In light of the growing aging homeless population, states should address structural barriers that homeless individuals face in accessing these programs.

Our study has limitations. Given the lack of prior work examining caregiving in homeless-experienced populations, we developed and applied a definition for caregiving need. This definition may have resulted in an over- or underestimation of caregiving needs. However, characteristics included in our caregiving need definition were drawn from prior research and are widely cited as contributors to caregiving need in nationally representative samples of older populations. ${ }^{28-32}$ Some participants may not have considered all potential sources of caregiving support when we asked whether they received assistance, potentially leading to an overestimation of unmet need. Individuals with the same level of disability, depending on their culture, age, and gender, can respond differently to instruments used to measure functional status. ${ }^{55}$ To minimize this potential bias, we administered an IADL tool developed for use in homeless populations. ${ }^{24}$ Some of our sample characteristics, including participant rates of current homelessness and institutional residence, are reflective of nationally representative data on homeless populations. ${ }^{56}$ However, we recruited participants from California, which may restrict the generalizability of our findings with respect to access to caregiving services. For example, California is one of few states that allow IHSS recipients to hire family members as caregivers, which may facilitate access to additional caregiving options for housed individuals.

This is the first study to describe caregiving need among older homeless-experienced adults and examine factors contributing to their unmet need. The high prevalence of unmet need in this vulnerable population has implications for individual health outcomes and future health system expenditures. By tailoring existing community caregiving resources to accommodate the needs of homeless-experienced older adults, we may better address their care needs while avoiding adverse and costly outcomes.

Acknowledgements: We would like to thank the participants for sharing their stories and the incredible leadership from our Community Advisory Board.

Corresponding Author: Wagahta Semere, MD, MHS; Division of General Internal Medicine, University of California, San Francisco (UCSF) and Zuckerberg San Francisco General Hospital and Trauma Center, San Francisco, CA, USA (e-mail: wagahta.semere@ucsf.edu).

Author Contribution Study concept and design: Semere and Kushel; acquisition of subjects and/or data: Kushel and Guzman; analysis and interpretation of data: Valle, Guzman, Semere, Kaplan, and Kushel; and preparation of manuscript: Semere, Kaplan, Valle, Guzman, Ramsey, and Kushel. No other individuals contributed substantially to this research or to the preparation of this manuscript.

Funding This work was supported by the National Institute on Aging at National Institute of Health under Grants R01AG041860, 2K24AG046372 awarded to Dr. Kushel. Dr. Semere is supported by a National Center for Advancing Translational Sciences, National Institutes of Health award through UCSF-CTSI (KL2 TR001870). The $N I H$ had no role in the data collection, analysis, or writing of the manuscript. The contents and views in this manuscript are those of the authors and should not be construed to represent the views of the National Institutes of Health. 


\section{Declarations:}

Conflict of Interest: The authors declare that they do not have a conflict of interest.

\section{REFERENCES}

1. Hahn JA KM, Bangsberg DR, Riley E, Moss AR. Brief Report: the aging of the homeless population: fourteen-year trends in San Francisco. J Gen Intern Med. 2006;21(7):775-8.

2. Brown RT KD, Bharel M, Mitchell SL. Geriatric syndromes in older homeless adults. J Gen Intern Med. 2012;27(1):16-22.

3. Brown RT, Hemati K, Riley ED, Lee CT, Ponath C, Tieu L, et al. Geriatric Conditions in a Population-Based Sample of Older Homeless Adults. The Gerontologist. 2017;57(4):757-66.

4. U.S. Department of Housing and Urban Development. 2016 Annual homelessness assessment report. Available at: https://www. hudexchange.info/resource/5178/2016-ahar-part-1-pit-estimates-ofhomelessness/. Accessed 4 Feb 2022.

5. Khullar DCD. Health, Income, \& Poverty: Where We Are \& What Could Help. Health Affairs Health Policy Brief. 2018.

6. Banks LM, Kuper H, Polack S. Poverty and disability in low- and middleincome countries: A systematic review. PloS One. 2017;12(12):e0189996-

7. O'Carroll A, Wainwright D. Making sense of street chaos: an ethnographic exploration of homeless people's health service utilization. Int $\mathrm{J}$ Equity Health. 2019;18(1):113.

8. Watts MOMM, Chidambaram P. Medicaid Home and Community-Based Services Enrollment and Spending. Feb 2020.

9. Hawkins RL AC. Disappearing acts: The social networks of formerly homeless individuals with co-occurring disorders. Soc Sci Med. 2007;65(10):2031-42

10. Genworth Cost of Care Survey 2018, conducted by CareScout $\AA^{\text {Available }}$ at: https://www.genworth.com/aging-andyou/finances/cost-of-care. html. Accessed 4 Feb 2022.

11. Sandel MSR, Ettinger de Cuba S, et al. Unstable Housing and Caregiver and Child Health in Renter Families. Pediatrics. 2018;141(2):e20172199.

12. Ettinger de Cuba S CM, Bovell-Ammon A, et al. Loss Of SNAP Is Associated With Food Insecurity And Poor Health In Working Families With Young Children. Health Aff (Millwood). 2019;38(5):765-73.

13. Lee CT GD, Ponath C, Tieu L, Riley E, Kushel M. Residential patterns in older homeless adults: Results of a cluster analysis. Soc Sci Med. 2016;153:131-40.

14. Burnam MA KP. Methodology for Obtaining a Representative Sample of Homeless Persons The Los Angeles Skid Row Study. Evaluation Review. 1988.

15. Henry M WR, Rosenthal L, Shivji A. The 2017 Annual Homeless Assessment Report (AHAR) to Congress. Part 2: Estimates of Homelessness in the United States. Washington: DC: The U.S. Department of Housing and Urban Development: Office of Community Planning and Development. 2017

16. Homeless Emergency Assistance and Rapid Transition to Housing Act of 2009. Definition of homelessness. PL-, Sec. 1003(2009). Definition of homelessness. 2009:P.L. 111-22.

17. Dunn LB JD. Enhancing informed consent for research and treatment. Neuropsychopharmacology. 2001;24(6):595-607

18. Gielen AC MK, Wu AW, O'Campo P, Faden R. Quality of life among women living with HIV: The importance violence, social support, and self care behaviors. Soc Sci Med. 2001;52(2):315-22

19. Ware JE KM, Keller SD. A 12-item short-form health survey: Construction of scales and preliminary tests of reliability and validity. Med Care. 1996;34(3):220-33.

20. Babor TF HBJ. Alcohol screening and brief intervention: Dissemination strategies for medical practice and public health. Addiction. 2000;95(5):677-86.

21. Smith PC SS, Allensworth-Davies D, Saitz R. Primary Care Validation of a Single-Question Alcohol Screening Test. J Gen Intern Med. 2009;24(7):783-8.

22. Humeniuk R HES, Ali R, Poznyak V, Monteiro M. The alcohol, smoking and substance involvement screening Test (ASSIST): Manual for use in primary care. World Health Organization. 2010.

23. S Katz. Assessing self-maintenance: Activities of daily living, mobility, and instrumental activities of daily living. J Am Geriatr Soc. 1983;31(12):721-7.
24. Sullivan G DL, Burnam A, Koegel P. Validation of the brief instrumental functioning scale in a homeless population. Psychiat Serv. 2001;52:1097-9.

25. Guralnik JM SE, Ferrucci L, et al. A short physical performance battery assessing lower extremity function: association with self-reported disability and prediction of mortality and nursing home admission. J Gerontol. 1994;49(2):M84-M95.

26. Bland RC NS. Mild dementia or cognitive impairment: The Modified MiniMental State examination (3MS) as a screen for dementia. Can J Psychiat. 2001;46(6):506-10.

27. Bravo G HR. Age- and education-specific reference values for the MiniMental and modified Mini-Mental State Examinations derived from a non-demented elderly population. Int $\mathrm{J}$ Geriatr Psychiatry. 1997; 12(10): 1008

28. National Academies of Sciences E, and Medicine. Families caring for an aging America: Older Adults Who Need Caregiving and the Family Caregivers Who Help Them. Washington, DC: The National Academies Press. 2016

29. Abdi S SA, Borilovic J, de Witte L, Hawley M. Understanding the care and support needs of older people: a scoping review and categorization using the WHO international classification of functioning, disability and health framework BMC Geriatr. 2019;19(1):195.

30. Riffin C VNP, Wolff JL, Fried T. Family and Other Unpaid Caregivers and Older Adults with and without Dementia and Disability. J Am Geriatr Soc. 2017;65(8):1821-8.

31. Bergen G, Stevens MR, Burns ER. Falls and Fall Injuries Among Adults Aged $\geq 65$ Years - United States, 2014. MMWR Morb Mortal Wkly Rep. 2016;65(37):993-8.

32. Pavasini R, Guralnik J, Brown JC, di Bari M, Cesari M, Landi F, et al. Short Physical Performance Battery and all-cause mortality: systematic review and meta-analysis. BMC Med. 2016;14(1):215.

33. National Health and Aging Trends Study. National Institute on Aging. NIA U01AG32947. Produced and distributed by www.nhats.org. Accessed 4 Feb 2022.

34. Courtney-Long EA CD, Zhang QC, et al. Centers for Disease Control and Prevention. Prevalence of Disability and Disability Type Among Adults-United States, 2013. Morb Mortal Wkly Rep. 2015;64(29):777-83.

35. Freedman VA SB. Disability and Care Needs Among Older Americans. Milbank Q. 2014;92(3):509-41.

36. Brown RT GD, Kaplan LM, Ponath C, Lee CT, Kushel MB. Trajectories of Functional Impairment in Homeless Older Adults: Results from the HOPE HOME Study. PLoS One. 2019;14(8):e0221020.

37. Brown RT D-RL, Boscardin J, Lei SJ, Steinman MA. Functional Impairment and Decline in Middle Age: A Cohort Study. Ann Intern Med. 2017;167(11):761-8.

38. Desai MM LH, Weeks JD. Unmet need for personal assistance with activities of daily living among older adults Gerontologist. 2001;41:82-8.

39. Allen S MV. The prevalence and consequences of unmet need. Contrasts among older and younger adults with disability. Med Care. 2007;35(11):1132-48

40. California Department of Social Services. In-Home Supportive Services (IHSS) program. Available at: https://www.cdss.ca.gov/in-home-supportive-services. Accessed 4 Feb 2022

41. CA Welf. \& Inst. California Dept. of Social Services Manual of Policies and Procedures. Code § 12300(a) § 30-701(o)(2)

42. Joe Molica DB. San Francisco Expands Access to In-Home Supportive Services for Formerly Homeless Older Adults and People with Disabilities in Permanent Supportive Housing. San Francisco: San Francisco Human Services Agency; November 29, 2021.

43. Ramsey C, Kushel M. California Offers In-Home Support, and Homeless Older Adults Should Have Access Too. California Health Report. Available at: https://www.calhealthreport.org/2017/10/24/california-offershome-supporthomeless-older-adults-access/. Accessed 4 Feb 2022.

44. Henry M, Mahathey A, Morril T, Robinson A, Shivji A, Watt R. The 2019 Annual Homeless Assessment Report (AHAR) to Congress. In: The U.S. Department of Housing and Urban Development, ed; 2019.

45. Clift T. Dozens of homeless have been kicked out of Sacramento hotels used as shelters during COVID. The Sacramento Bee. Sacramento, California; June 17, 2021.

46. Gruneir A FJ, Camacho X, Gill SS, Bronskill SE. Gender differences in home care clients and admission to long-term care in Ontario, Canada: a population-based retrospective cohort study. BMC Geriatrics. 2013;13:48.

47. Gobbins RJJ, van Assen MA. The Prediction of ADL and IADL Disability Using Six Physical Indicators of Frailty: A Longitudinal Study in the Netherlands. Curr Gerontol Geriatr Res. 2014;2014:1-10. 
48. Gill TM MT, Barry LC, Allore HG. Risk factors for disability subtypes in older persons. J Am Geriatr Soc. 2009;57(10):1850-5

49. Rothman MD L-SL, Gill TM. Prognostic significance of potential frailty criteria. J Am Geriatr Soc. 2008;56(12):2211-6.

50. Kushel M. Older homeless adults: can we do more? J Gen Intern Med. 2012;27(1):5-6

51. Doty P. Cost-effectiveness of Home and Community-Based Long-term Care Services. US HHS/ASPE Office of Disability, Aging and Long-Term Care Policy. 2000. Available at: https://aspe.hhs.gov/system/files/pdf/ 73916/costeff.pdf. Accessed 4 Feb 2022.

52. FACT SHEET: Biden-Harris Administration Delivers Funds to Support the Health of Older Americans. White House Briefing Room. May 3, 2021 Available at: https://www.whitehouse.gov/briefing-room/ statementsreleases/2021/05/03/fact-sheet-biden-harris-administration-delivers-funds-to-support-the-health-of-olderamericans/. Accessed 4 Feb 2022.
53. American Rescue Plan Act of 2021. Public Law 117-2. H.R. 1319. Pg. 242. Sect 9817. Suppl No. 135, Stat. 4.

54. Implementation of American Rescue Plan Act of 2021 Section 9817: Additional Support for Medicaid Home and Community-Based Services during the COVID-19 Emergency. Report No. CMS, SMD \#21-003. Available at: https://www.medicaid.gov/federal-policy-guidance/downloads/smd21003.pdf. Accessed 4 Feb 2020.

55. Fleishman JA SW. Altman Impact of Differential Item Functioning on Age and Gender Differences in Functional Disability. BM J Gerontol BPsychol. 2002;57(5):S275-S84.

56. Homelessness USICo. Opening Doors: Federal and Strategic Plan to Prevent and End Homelessness, As Amended in 2015. 2015

Publisher's Note: Springer Nature remains neutral with regard to jurisdictional claims in published maps and institutional affiliations. 